\title{
Cui Bono, Benefit Corporation? AN EXPERIMENT INSPIRED BY SOCIAL ENTERPRISE LEGISLATION IN GERMANY AND THE US*
}

\author{
Sven Fischer, Sebastian J. Goerg, and Hanjo Hamann
}

This version: December 8, 2014

\begin{abstract}
How do barely incentivized norms impact incentive-rich environments? We take social enterprise legislation as a case in point. It establishes rules on behalf of constituencies without institutionalized means of enforcement. By relying primarily on managers' otherregarding concerns whilst leaving corporate incentive structures unaltered, how effective can such legislation be? We ran a laboratory experiment with a framing likened to German corporate law which traditionally includes social standards. Our results show that a stakeholder provision, as found in both Germany and more recent US regulation, cannot overcome material incentives. Yet even in the absence of adverse incentives the stakeholder duty does not foster other-regarding behavior. Our experiment illustrates the paramount importance of taking into account both incentives and framing effects when designing institutions. We tentatively discuss potential policy implications for social enterprise legislation and the stakeholder debate.
\end{abstract}

JEL classification: A12, D01, D03, L21, M14, M52

Keywords: stakeholder value, social enterprise, benefit corporation, corporate law, experiment

* Sven Fischer: Max-Planck-Institute for Research on Collective Goods, Kurt-Schumacher-Str. 10, 53113 Bonn, Germany. Sebastian J. Goerg: Department of Economics, Florida State University, 113 Collegiate Loop, Tallahassee, FL 32306-2180, USA. Hanjo Hamann: Max-Planck-Institute for Research on Collective Goods. Corresponding author: Hanjo Hamann (hamann@coll.mpg.de)

We are grateful for helpful comments by Eckart Büren, Michael Dorff, Christoph Engel, Andreas Engert, Kristoffel Grechenig, Oliver Himmler, Klaus-Ulrich Schmolke and two anonymous referees. 


\section{Introduction}

"Don't tell me where your priorities are. Show me where

you spend your money and I'll tell you what they are."

James W. Frick (University of Notre Dame)

Corporate greed is one of the most persistent and defining buzzwords of our day 1 It is said to have caused economic crises world-wide, and in one of the more unlikely motion picture sequels ever to be made, we see Gordon Gekko suggesting: "I once said Greed is good. Now it seems it's legal.'2 2 Legal though it may be, this alleged greed has also given new thrust to a movement known as CSR, corporate social responsibility (e.g., Bénabou and Tirole 2010). Firms increasingly care about their reputation and discover the social purpose of doing commercial business. The "Rise of the Social Enterprise" is seen as the "Future of the Law" (Timmerman et al. 2011) and a "New Fourth Sector" of social enterprise forms emerges all over the world (Mickels 2009: 279) - from the United Kingdom ("community interest companies" since 2005) to Canada's British Columbia ("community contribution companies" since 2012), and the US ("benefit corporations" since 2010, see Plerhoples 2012, Murray 2012; Kanig 2013) $!^{3}$

Despite the attention that these new instruments receive, their behavioral mechanisms are critically understudied. As a case in point, benefit corporations in the US have been gradually introduced since 2010 (in Delaware August 2013) on the basis of model legisla-

1 Bookstore shelves are loaded with titles like Pigs at the Trough: How Corporate Greed and Political Corruption Are Undermining America (A. Huffington 2003), All the Justice Money Can Buy: Corporate Greed on Trial (S. Prakash 2011), or The Speech: A Historic Filibuster on Corporate Greed and the Decline of Our Middle Class (B. Sanders 2011). Corporate greed even alerted the legislator, resulting in the Sarbanes-Oxley Act (cf. DeCelestino 2006). As an anonymous referee noted, the increased attention to both corporate greed and corporate social responsibility can easily be traced using n-gram data (see fig. 2 in the Appendix).

2 "Wall Street: Money Never Sleeps", a film by Oliver Stone, 20th Century Fox, 2010.

3 In the US, another new vehicle for social entrepreneurship is the "low-profit limited liability company", L3C (Murray and Hwang 2011), which is closer in spirit to tax-exempt non-profits under USC § 501(c)(3) than to traditional corporations (cf. Artz, Gramlich and Porter 2012: 232). 
tion that deviates from classical business corporations in little more than one respect: "A director of a benefit corporation has a duty to consider the effects of any action or inaction upon the stakeholders of the benefit corporation.' 4 Yet in most other respects, benefit corporations are the "same as a traditional corporation" face the same material incentives as in a classical corporation: They are still elected by shareholders and accountable exclusively to them ${ }^{6}$ With such incentives in a competitive environment, how effective, as an institution, can the new accountability rule of benefit corporations be?

To be effective, the accountability rule has to perform two functions: It has to be both a right and a duty: $]^{7}$ i.e., it has to serve an enabling function - providing "legal protection to directors for factoring non-financial interests into decisions" (Artz, Gramlich and Porter 2012: 232 $)^{8}$ - as well as a restraining function to make the company "stay mission-driven [...] by institutionalizing the values, culture, processes, and high standards put in place by founding entrepreneurs." (Yvon Chouinard, Founder of Patagonia, see Murray 2013: 486). Since socially-minded corporations may be hugely profitable (see the case study of Ben \& Jerry's in Artz, Gramlich and Porter 2012: 232) and since "becoming a benefit corporation gives a company the opportunity to be more competitive than traditional corporations" (André 2012: 147), they are attractive even for purely profit-seeking investors, thus en-

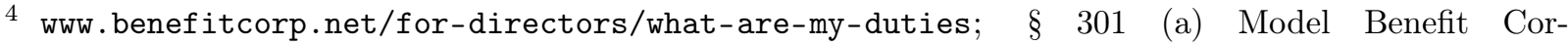
poration Legislation (MBCL) at http://benefitcorp.net/storage/documents/Model_Benefit_ Corporation_Legislation.pdf

5 See Legal FAQs: What is a Delaware Public Benefit Corporation? (www.benefitcorp.net/storage/ documents/Implications_of_Becoming_a_DE_Public_Benefit_Corporation.pdf), p. 1 .

6 See www.benefitcorp.net/for-directors/guidance-considering-stakeholder-interests shareholders "are listed first, and remain the only stakeholder entitled to bring a legal action"). Other stakeholders may at best be entitled derivatively by the articles or bylaws, see $\S 305$ (b) (2) MBCL.

7 Similarly, Munch (2012: 195): "The new laws must not only protect these businesses' pursuit of a dual missions; they must keep them accountable in both as well."

8 Without this protection, directors violate their fiduciary duties by considering interests other than those of shareholders. See the official MBCL comment, p. 14 in http://benefitcorp.net/storage/ documents/Model_Benefit_Corporation_Legislation.pdf. This aspect was previously studied (e.g., Greenfield and Kostant 2003), but does "not seem to motivate the average director to move beyond the shareholder wealth maximization norm" (Murray 2013: 505). 
dangering any informal safeguard to ensure socially-minded management of the company. So unless directors are restrained effectively, the benefit corporation's societal vision can fall prey to managerial "abuse" (Munch 2012: 171) as soon as the first, socially-committed generation of investors leaves the firm. Probing the restraining function under conditions of managerial competition is thus a "stress test" for benefit corporation legislation as a whole 9

Such a test is difficult in the US environment, where benefit corporations are perceived as a curious novelty and compete with classical corporations. A better environment to test the underlying behavioral assumptions can be found in Germany, where to some extent every company is a benefit corporation: German law has always put emphasis on corporate stakeholders such as employees and creditors, and even outside constituencies like the "general public" (Jürgens et al. 2000; Fiss and Zajac 2004).10 At least since 1937, German corporation law has held directors accountable for considering the interests of diverse stakeholders ${ }^{11}$ which the German Corporate Governance Code summarizes as follows:

"The Management Board is responsible for independently managing the enterprise in the interest of the enterprise, thus taking into account the interests of the shareholders, its employees and other stakeholders, with the objective of sustainable creation of value." (Sec. 4.1.1 GCGC rev. 2009), where "stake-

9 We thank an anonymous reviewer for this metaphor.

10 This mirrors the more basic understanding of German law that any private property shall be used not least to advance the common good, as laid down in art. 153 (3) 2 of the Weimar Constitution 1919 and art. 14 (2) 2 of the Bonn Constitution 1949 (Grundgesetz).

11 Sec. 70 of the Stock Corporation Act 1937 read: "The Management Board has to independently manage the company as required by the well-being of the enterprise and its workforce and the common good of populace and Reich." Despite its conspicuous timing, this was a statement less of Third Reich ideology than of "a changing economic attitude which had progressively gained popularity since the days after World War One and which today, more than ever, is a crucial requirement for any business undertaking." (Schmidt and Meyer-Landrut 1961: 436). By 1965, legislators considered stakeholder accountability so intuitive that they no longer saw a need to prescribe it expressly, cf. parliamentary print matter 4/171 (http://dipbt.bundestag.de/doc/btd/04/001/0400171.pdf), p. 121. 
holders" consist of at least "employees, managers, customers, suppliers and the general public" (Von Werder 2010: par. 353).

This environment strongly resembles the new benefit corporation regime and should thus provide both valuable experiences and a clean testing ground for the assumption that stakeholder accountability materially restrains managerial behavior. However, corporate boards are rich institutional arrangements with intransparent decision-making procedures, which hinders identification of causation. Board members are also high-profile decision makers concerned with confidential high-stake decisions, and difficult to engage for behavioral field research. Therefore, the causal assumption of stakeholder accountability cannot be tested directly in the field, ${ }^{12}$ and since we could not find a convincing difference-in-differences approach, the most suitable research design in the present context is a controlled laboratory experiment which introduces the corporate decision-making context by imitating its key features (esp. incentives and framing).

\section{Design}

As our workhorse we rely on the widely-used dictator game (Forsythe et al. 1994).13 This non-strategic decision environment best reflects the interaction between a corporation and stakeholders which are not represented in corporate decision-making and have no immediate bargaining or sanctioning power. Our design therefore departs from Greenfield and Kostant (2003), where corporate decision-making was seen as a bargaining process and thus operationalized as an ultimatum game. While this perspective certainly has merit,

12 This could be ameliorated by conducting questionnaire surveys (Adams et al. 2011) or interviews (Manâa 2010). Yet, a concern about causation remains. Furthermore, norms are difficult to evaluate in the field compared to laboratory settings. See Burks and Krupka (2012) as an example for the elicitation in the field and Krupka and Weber (2013) as an example for the lab.

13 One participant (the proposer) receives an endowment which she is free to keep for herself or share in any way she wishes with a second participant (the receiver). As the proposer has no material incentive to offer any amount, the game is frequently used to measure other-regarding concern. 
it does not address stakeholder value so much as non-myopic shareholder value: In the ultimatum game, responders have veto power and, therefore, do not resemble powerless stakeholders. Since the specific value added by stakeholder legislation is to enable corporate social responsibility towards agents that have no discernible influence in the company, the dictator game provides an appropriate representation. Put differently: While we do not believe that stakeholder orientation implies spending corporate money on purposes entirely unrelated to the corporation's business, we argue that stakeholder orientation is effective only if it benefits constituencies which do not demonstrably increase shareholder profits in return - or else classical fiduciary duties ought to suffice.

We vary our workhorse to create five treatments, which we mention briefly, but explain thoroughly in the next subsection: The Control serves as a benchmark in which ownermanagers divide a fixed pie between themselves and other stakeholders, represented by a charitable organization. In four additional treatments this division is decided upon by hired managers, in a $2 \times 2$-factorial design with variations of incentives (Competition vs. NoCompetition) and verbal framing which either did or did not include a stakeholder duty (Stake vs. NoStake). Our experimental design thus unpacks corporate decision-making by systematically varying the three factors agency, incentives and framing (see Table 1).

With regard to agency and incentives, we were inspired by (but did not exactly replicate) the experimental paradigm introduced by Hamman et al. (2010).14 With regard to framing, we used the exact wording of the German Corporate Governance Code (GCGC), as cited above. It is widely recognized in experimental economics and social psychology that the verbal framing of a decision problem plays an important role in decision making (see, e.g., discussion in Abbink and Schmidt, 2006). Frames are believed to trigger different norms,

$1 \overline{4}$ This paradigm used competition among agents as an enforcement device for their principal and should thus provide even more effective enforcement (since it requires no justification and incurs no costs) than the latent threat of shareholder suits under $\S 301$ (a) MBCL. By supplanting the "right to sue" with a "right to dismiss", we thus implemented a more conservative test to obtain an upper bound on stakeholder interests' enforcement level. 
create focal points, and affect beliefs or preferences. While the effect of frames has not yet been tested explicitly in delegation settings, general findings suggest that they should matter (e.g., Berninghaus et al., 2008). Dufwenberg et al. (2011) theorize that frames affect beliefs which in turn shape motivation and choices. For our design, these findings suggest that framing subjects with a GCGC excerpt will affect their belief about norms in this context, which in turn shapes their own motivation and decisions. Thus, while frames do not affect fundamental incentives in a strict sense, they are likely to shape motivations and decisions more indirectly.

\section{II.1. Treatments}

\section{Control: Manager owned company}

The control is a simple dictator game with three modifications to better approximate a corporate decision-making environment: First, we applied a business framing by letting participants act in the role of a "company owner" deciding on an investment that affects both her company and the "general public". Second, our frame invoked high stakes by endowing subjects with 10,000 Taler (at an exchange rate of 800 Taler $=1$ Euro) which they were supposed to allocate in any division of integers between the firm and the general public. Third, the general public was not modeled by another participant but by a charity to which donations were made. This best approximated the general public as a stakeholder explicitly mentioned both in Sec. 4.1.1 GCGC and $\S 301$ (a) MBCL, and made subjects' behavior meaningful outside the lab. This modified dictator game is an original contribution to the literature, designed specifically for the present study.

The dictator game decision was repeated over 10 periods, after which one period was randomly determined and the corresponding allocation implemented. This treatment serves as a baseline and provides a measure for the degree of subjects' other-regarding preferences 
in the role of a firm owner facing a charity.

\section{NoCompNoStake: Berle-Means company with entrenched manager}

Building on the baseline game, the second treatment introduced an agent into the decision structure. The agent was framed as a manager whom the company owner, i.e. the sole shareholder, had to hire by law and who would proceed to make the allocation on the shareholder's behalf. We thus implemented a separation of ownership and control, as the defining feature of corporations in the tradition of Berle and Means (1932). To make this even more explicit, subjects were informed that

A manager is responsible for independently managing the enterprise. According to German law, a manager is not bound by the expectations and demands of the shareholder.

The roles of shareholder and manager were randomly assigned at the beginning of the experiment, and fixed throughout. Each shareholder was partner-matched with one manager who had to be continually hired over all 10 periods ${ }^{15}$ The manager received a fixed wage of 300 Taler for every period, exogenously provided by the experimenter to keep the amount available for distribution constant between treatments.

This treatment provides a measure for managers' other-regarding behavior when having full discretion over a stock of other people's money. In combination with Control it allows us to investigate whether subjects in the role of managers, acting on behalf of the company owners (i.e., shareholders), make the same decisions as the owners would. Thus, this treatment allows to isolate the effect of introducing agency, with no sanctioning mechanisms on top.

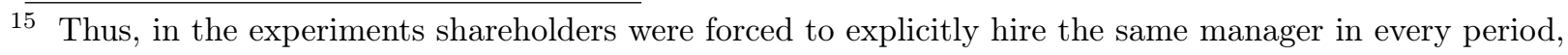
to keep our protocol constant across treatments. 


\section{CompNoStake: Berle-Means company with manager market}

The third treatment introduced new incentives. Following Hamman et al. (2010), those incentives took the form of managerial competition: The shareholder still had to delegate her decisions to a manager, but now she could choose one of three managers who were competing to be hired. Therefore, our partner-matched groups now contained four members: one shareholder and three managers, each identifiable by unique ID. At the beginning of each of the 10 periods the shareholder had to choose one of the three managers. If a manager was hired, she received an irrevocable wage of 900 Taler (otherwise nothing) for this period. ${ }^{16}$

To elicit the manager decisions, we employed the strategy method (Selten 1967) in a positional order protocol, i.e. managers decided after the shareholder had made her hiring decision but before knowing whether they had been hired or not. If a manager was hired, the corresponding allocation was implemented and disclosed to all group members at the start of the next period. More specifically, after the first period shareholders were given a list with all decisions by previously hired managers at the beginning of every round. Allocations chosen by non-hired managers were not disclosed to anyone. Thus we do not allow for a competition over wages, but only over decisions in favor of the shareholder. This resembles the situation outside the lab: Since the decisions of a manager have a higher impact on the value of a company (i.e., shareholder earnings) than the manager's wage does, shareholders certainly pay more attention to the manager's decisions.

$1 \overline{6}$ This is equal in expected value to the wage in treatment NoCompNoStake, and qualitatively equivalent to the payment scheme of Hamman et al. (2010: 1830). 


\section{NoCompStake: Stakeholder duty without manager market}

In this treatment we introduced a stakeholder duty in the spirit of the German Corporate Governance Code. The procedure was identical to the one in NoCompNoStake, but for one very subtle variation: We added a short excerpt from Sec. 4.1.1 of the German Corporate Governance Code to the paragraph about managers' duties (italicized here, but not in the original).
A manager is responsible for independently managing the enterprise. According to German law, a manager is not bound by the expectations and demands of the shareholder; rather he "manages the enterprise in the interest of the stakeholders (e.g. shareholders, employees, customers, general public), with the objective of sustainable creation of value." (Sec. 4.1.1 of the German Corporate Governance Code)

This treatment, in comparison with NoCompNoStake, allows us to isolate the impact of the non-binding stakeholder provision. Since both our quote from Sec. 4.1.1 GCGC and our instructions (see the explanations for Control) explicitly mention the general public, participants should easily see the connection.

\section{CompStake: Stakeholder duty with manager market}

Treatment CompStake was identical to CompNoStake, except that the same excerpt from the German Corporate Governance Code as in NoCompStake was presented to the participants.

This treatment, in comparison with CompNoStake, allows us to isolate the impact of the non-binding stakeholder provision under competition among managers. In addition, the comparison with NoCompStake allows us to investigate whether competition hampers 
the effectiveness of a non-binding stakeholder provision.

Table 1 summarizes our treatments.

Table 1.: Treatments

\begin{tabular}{|c|c|c|c|c|c|}
\hline \multirow{2}{*}{\multicolumn{6}{|c|}{ Treatment variables: (5 treatments varying agency, incentives and framing) }} \\
\hline & & & & & \\
\hline $\begin{array}{l}\text { Separation of } \\
\text { ownership and control }\end{array}$ & - & $\checkmark$ & $\checkmark$ & $\checkmark$ & $\checkmark$ \\
\hline $\begin{array}{l}\text { Competition via } \\
\text { manager market }\end{array}$ & - & - & $\checkmark$ & - & $\checkmark$ \\
\hline $\begin{array}{l}\text { Stakeholder duty } \\
\text { present }\end{array}$ & - & - & - & $\checkmark$ & $\checkmark$ \\
\hline \multicolumn{6}{|c|}{ Experiment: (293 subjects in 120 matching groups) } \\
\hline Subjects & 33 & 44 & 84 & 44 & 88 \\
\hline Groups & 33 & 22 & 21 & 22 & 22 \\
\hline
\end{tabular}

Note: Each matching group is one independent observation. In Control, owners decided on their own, in NoComp-treatments, one manager was paired with one owner and in Comp-treatments, three managers were paired with one owner.

\section{II.2. Experimental Procedure}

The experiment was conducted at the BonnEconLab of the University of Bonn. In total 293 subjects participated in the study. They were randomly invited from a pool of $6,000+$ registered subjects via an online-recruiting database ORSEE (Greiner, 2004). Out of the 293 participants in our sample, 178 were female (60.75\%). Participants ranged in age from 18 to 55 years, with an average age of 22.86 years. With the exception of two, all were either university students or already had a university degree. In total, 33.79\% had a background 
in natural sciences, psychology or medicine, $34.47 \%$ in law, politics or economics, and $29.69 \%$ in other subjects, including the humanities. $90.1 \%$ of the subjects were native speakers of German, the experiment's language of instruction. Table 1 gives the number of independent observations as well as the number of subjects per treatment.

Upon arrival, subjects were seated in separate cabins and received instructions. These instructions were read aloud, with subsequent control questions being distributed afterwards. The experiment started only after all subjects had correctly answered all questions. Subsequent interactions were entirely computer-mediated, through a program developed in z-Tree (Fischbacher, 2007) ${ }^{17}$

To avoid confounding the general willingness to donate to a charity with the willingness to donate to a specific one, we revealed the charity only after all decisions were made. However subjects were told at the beginning of the experiment that the charity had the seal of approval by the German Central Institute for Social Issues (DZI), ensuring that the charity was tested and well-reputed.

After the experiment, subjects answered a questionnaire about socio-demographic details and motives for their decisions. In addition, all subjects completed the Justice Sensitivity Questionnaire (Schmitt, Gollwitzer, Maes, and Arbach 2005), with scales for justice sensitivity from the perspectives of victims, observers, and perpetrators.

Finally, subjects were paid individually for one randomly chosen period. For each subject in the role of active (chosen) manager, we put the amount that this subject had, in this round, assigned to charity into a transparent jar.18 The last subject supervised the counting of the total donation (the accumulated amount in the jar) and the online transfer to charity. All subjects were informed about this procedure in the instructions. Including instructions,

17 Screenshots of the computer screens are given in the Appendix.

18 We used this jar so that all subjects could see that we actually accumulated charity donations and did not empty the jar between paying subjects. 
control questions, 10 decision periods, post-questionnaire and payments, each session lasted between one and two hours with average payments per subject of EUR 10.95 (i.e., about 14-15 USD).

\section{Hypotheses}

The baseline of our experiment was provided by the Control treatment. The rich experimental literature on dictator games shows that most proposers (on average $64 \%$ ) transfer some non-trivial positive amount (on average $28.3 \%$ ) to the receivers (Engel 2010: 5889). Our recipient was a charity, which has been shown to increase average redistribution rates by as much as threefold and to reduce the number of purely selfish subjects (Eckel and Grossman 1996: 187). On the other hand we applied a business framing which has been shown to move behavior closer to rational predictions (Arlen et al. 2002). But even business-framed decision experiments "do suggest some role for such other-regarding preferences, albeit only a weak one." (Arlen et al. 2002: 32). In our control treatment we therefore expect positive alas slightly smaller transfers than in standard dictator experiments.

Introducing managers in NoCompNoStake and NoCompStake puts agents in charge of financial decisions without restraining them to the principals' interests. In such cases, the managers can expropriate funds as they see fit (e.g., Shleifer and Vishny 1997: 742). Given this liberty over corporate funds, managers will likely engage in some mental balancing, assessing their income relative to that of other corporate stakeholders. In our treatments without competition, this lateral comparison figured prominently in that agents faced a secure, fixed wage of 3,000 Taler $\left(10^{*} 300\right)$ while principals were paid out of a budget of 10,000 Taler from one random round. If agents transferred to the charity as much as senders usually do in the dictator game (20 to $30 \%$ of their endowment), their principals would 
still be twice as well off as they themselves. However, experimental behavior often reflects inequality aversion (Fehr and Schmidt 1999; Bolton and Ockenfels 2000). An inequality averse manager would thus want to transfer more than senders in a standard dictator game.

Hypothesis 1: In treatments with entrenched managers, transfers are higher than in treatments with owner-managers (i.e., NoCompNoStake > Control and NoCompStake > Control).

Moving on from the simple entrenched manager case to one with three competing managers, we turn to Hamman et al. (2010) for an intuition of what to expect. In their treatments with competing agents, transfers initially equaled those in the condition without competition, but very quickly declined to half of those in the baseline condition (Hamman et al. 2010: 1832). Facing a market, managers needed to please the shareholders to be hired again and thus managers suppressed their own generosity. This was especially clear in the last round, where transfers exceeded previous ones by far, "driven largely by several agents [...] choosing to give away all $\$ 10$ in the final round, when there are no future possible repercussions from principals." (Hamman et al. 2010: 1831 fn. 10). Our CompNoStake and CompStake treatments differ from Hamman et al. (2010) primarily in terms of framing and the charity recipient. We assumed that this difference would not change the general pattern, but would merely affect its level.

Hypothesis 2: The manager market aligns the managers' behavior with the shareholders' interests and thus reduces the transfers (i.e., CompStake < NoCompStake and CompNoStake < NoCompNoStake).

Introducing the stakeholder frame into the treatments with and without the manager market, we adopted the naïve hypothesis underlying Sec. 4.1.1 GCGC (and the model legislation on benefit corporations): Stakeholder legislation serves to increase the consideration given to stakeholders. We should therefore expect higher transfers in both of these 
treatments if the legal framing does work at all.

Hypothesis 3: The introduction of the stakeholder duty increases the awareness for the stakeholders' concerns and thus transfers (i.e., NoCompStake > NoCompNoStake and CompStake > CompNoStake).

\section{Results}

Table 2 gives the summary statistics for each treatment 19 As expected we observe transfers that are strictly larger than zero in all five treatments. Mean and median transfers in treatment Control are at 961.61 and 334.5, respectively. Only 8 out of 33 subjects transferred zero throughout. Conversely, 4 out of 33 subjects transferred more than 2,000 Taler on average.

Table 2.: Summary statistics for transfers (out of an endowment of 10,000)

\begin{tabular}{lccc} 
Treatment & Mean & Median & Std. Dev. \\
\hline \hline & & & \\
Control & 961.61 & 334.5 & $1,629.53$ \\
NoCompNoStake & $5,407.22$ & 6,178 & $2,983.20$ \\
CompNoStake & $2,126.04$ & 709 & $3,203.60$ \\
NoCompStake & $3,924.54$ & 3,200 & $2,732.70$ \\
CompStake & $1,653.51$ & 137 & $2,910.47$ \\
& & & \\
\hline \hline
\end{tabular}

Note: In Comp-treatments we pooled all manager responses from the strategy method.

Our first hypothesis stated that transfers would be higher if decided upon by an agent rather than the principal. Testing the mean donations supports this conjecture. Across all

19 For a visualization of the donation distributions see figure 3 in the Appendix. As we will show later in this section, we observe large end-game effects in some of our treatments. Nevertheless, the relative ranking of mean donations between treatments is not affected by omitting the last period (Control 978.22; NoCompNoStake 5317.26; CompNoStake 1701.85; NoCompStake 3890.17; CompStake 1150.56). 
periods, transfers in treatments NoCompNoStake and NoCompStake are significantly higher than in the Control ( $\mathrm{p}<0.001$, two-sided Mann-Whitney u-test) ${ }^{20}$ Obviously, subjects in the role of managers prefer higher donations than in the role of manager-owners. We therefore conclude

Result 1: In treatments with entrenched managers, i.e., NoCompNoStake and NoCompStake, transfers are higher than in Control.

Our second hypothesis stated that manager competition would lower transfers. This is also confirmed by Figure 3 in the Appendix and by Table 2, Both treatments with competition (CompNoStake and CompStake) have significantly lower mean transfers than their counterparts without competition (NoCompNoStake and NoCompStake) (both with $\mathrm{p}<0.001$, Mann-Whitney u-test).

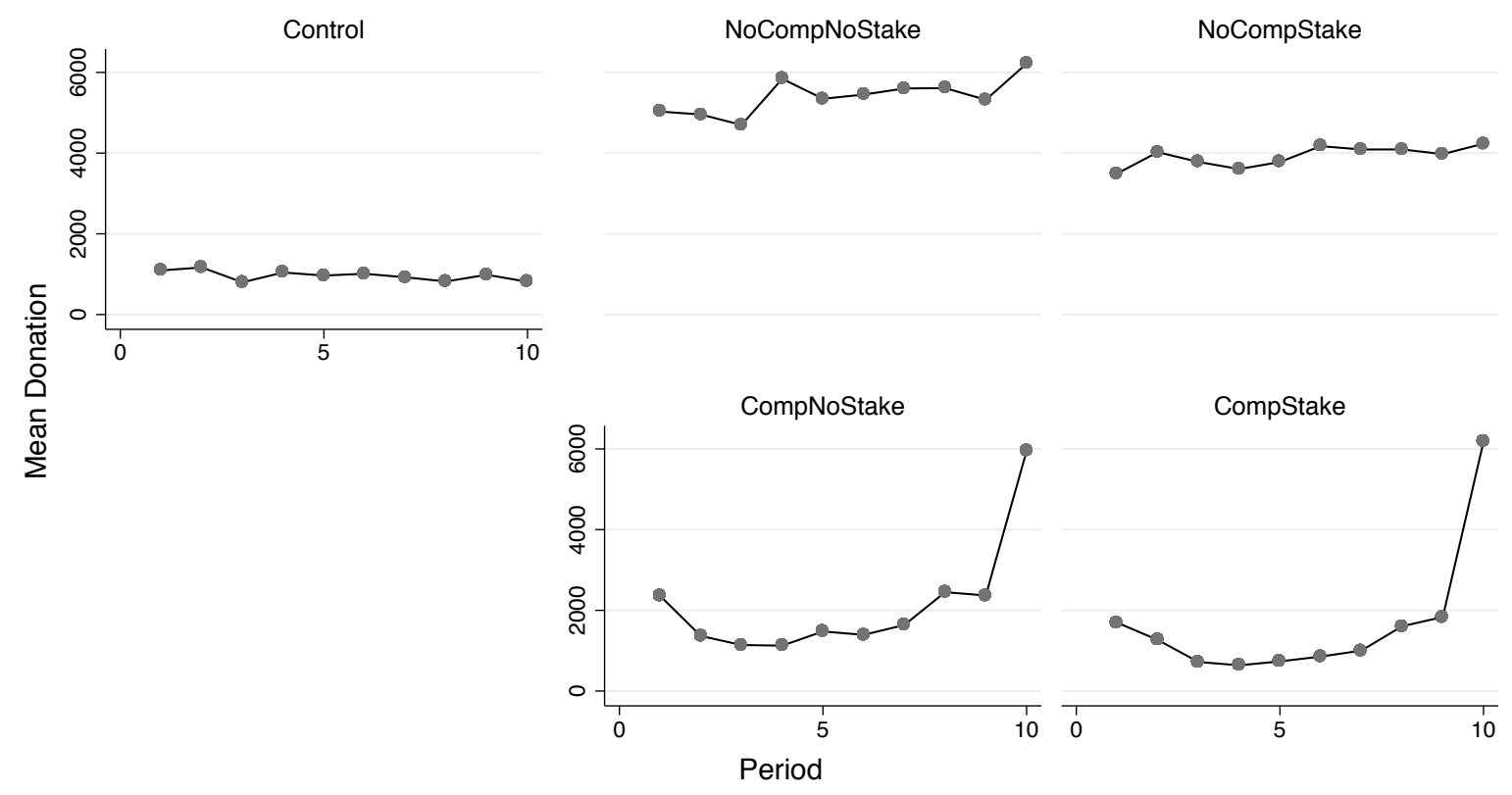

Figure 1.: Actual amount (out of 10,000) donated to Charity over time

20 Unless otherwise reported, all non-parametric pairwise comparisons are based on per-firm averages across all periods. 
Figure 1 demonstrates that this difference is already present in the first period: Transfers in CompNoStake and CompStake are significantly lower than the ones in NoCompNoStake and NoCompStake, respectively $(\mathrm{p}<0.001$ and $\mathrm{p}<0.01$, two-sided Mann-Whitney utests) ${ }^{21}$ This indicates that managers perceive a market-induced pressure to comply with shareholders' interests. However they initially seem to underestimate this pressure, so that transfers decrease even further after period 1.22

The hiring patterns that we observe in both Comp-treatments are very similar: Most shareholders select several different managers over the course of the experiment, and both the mode and median number of rounds in which a given manager is chosen equals 3 . However, roughly $50 \%$ of the time shareholders chose the same manager again, and $16.28 \%$ of the shareholders stick to the same manager throughout the entire experiment. ${ }^{23}$ What drives these hiring decisions and how do previous donations influence the probability of being chosen again? Table 3 shows the results of a mixed effects logit estimation, explaining whether a manager was selected again by the shareholder. The Variable Donation ${ }_{t-1}$ denotes the transfer in the previous round by the same manager ${ }^{24}$ The results show a significant selection effect: The more a manager donates, the less likely he will be selected again.

However, as the coefficients on period and the interaction of lagged donation with period show, this effect is diminishing over time. With every period, the unconditional probability of being chosen again increases. Over time, the effect of the lagged donations cancels out.

21 In the first period we included each individual decision in the test, as by virtue of the strategy method they were all statistically independent. In the following periods they were no longer independent, as subjects received feedback whether they were selected or not, given their previous decisions.

22 The differences between the treatments with and without competition are significant throughout periods 2 to 9 ( $\mathrm{p} \leq 0.001$ for comparisons CompNoStake vs. NoCompNoStake and CompStake vs. NoCompStake, two-sided Mann-Whitney u-tests).

23 For a distributional graph, see figure 4 in the Appendix.

24 Note that the independent variable is lagged and can thus only start with period 2. Results are qualitatively the same if we drop the last period or use the sum of all previous donations, refer to tables 5 and 6 in the Appendix. 
Table 3.: Mixed effects logit estimation of the probability of being chosen again

\begin{tabular}{|c|c|c|c|c|}
\hline & Coeff. & & Std. error & p-value \\
\hline Constant & -.7176 & & .6537 & 0.272 \\
\hline Donation $_{t-1}$ & -.00099 & $* * *$ & .0004 & 0.004 \\
\hline Period & .1470 & $* *$ & .0741 & 0.047 \\
\hline Donation $_{t-1} \times$ Period & .0001 & $* *$ & .00004 & 0.027 \\
\hline
\end{tabular}

$$
\mathrm{N}=387, \chi^{2}(3)=20.89, p=0.0001 * * *
$$

Note: Dependent variable is an indicator for whether the manager was chosen again at $t$. Data only from managers chosen at $(t-1)$ in either CompNoStake or CompStake 25

In period 8 the overall effect is still negative and significantly different from zero $(p<0.05$ Wald test) but in the last two periods, 9 and 10, it is no longer significant ( $p=0.312$ and $p=0.84$ Wald tests).

Since shareholders conditioned their hiring decisions on previous allocations, managers had an incentive to please them. We do not find any evidence that managers who were hired often change their transfer decisions over time before the very last period. However, managers who had continuously not been hired change their intended donations: Stated transfers of managers increase significantly with every period that they are not chosen $(\beta=396.58, \mathrm{p}<0.0001) .{ }^{26}$ But even regularly selected managers increased their transfers as soon as the pressure to comply with the shareholders' interest vanished: In the last period, average transfers no longer differed significantly from the ones in the treatments without a manager market $(\mathrm{p}>0.16$ for comparisons CompNoStake vs. NoCompNoStake and CompStake vs. NoCompStake, both two-sided Mann-Whitney u-tests).

Transfers in both competition treatments are therefore u-shaped (see figure 1 above):

26 Coefficient results from regressing the number of rounds previously not chosen on transfers with a random effect GLS regression, clusters on the group levels. 
They start at moderate levels, decrease over time to significantly lower values and resurge in the last period, where half of all hired managers transferred the entire 10,000 Taler to charity. This observation is in line with Hamman et al. (2010) and lends some support to their interpretation of "agents expressing displeasure at having aided in treating recipients unfairly in all previous rounds" (Hamman et al. 2000: 1831 fn. 10). We conclude

Result 2: The manager market aligns managers' behavior with the shareholders' interests. When market incentives vanish, managers significantly increase their transfers.

We now turn to the effectiveness of the stakeholder provision. We hypothesized - in line with the innocent assumption of Sec. 4.1.1 GCGC - that the stakeholder provisions would have the desired effect, i.e. increase consideration given to the general public, as proxied by the charity in our experiment.

However there is no significant difference between the two treatments with manager markets (CompStake vs. CompNoStake), neither overall nor in any single period $(\mathrm{p}=$ 0.244 overall, $0.15<\mathrm{p}<0.99$ for individual periods, two-sided Mann-Whitney u-test). This suggests that the stakeholder duty does not play itself out in the presence of an incentive to be hired. In fact, except for the last period, our three treatments CompNoStake, CompStake and Control are statistically indistinguishable $(0.12<\mathrm{p}<0.75$, MannWhitney u-test for between-treatment comparisons in all periods except period 10).

More surprisingly, we also observe no positive effect of the stakeholder duty in the treatments without manager market: Transfers to the charity are not higher in NoCompStake than in NoCompNoStake. In fact there is even an indication of the opposite, since the mean transfer in treatment NoCompStake is lower than in NoCompNoStake (Table 4). Over all periods this difference is close to significant $(\mathrm{p}=0.058$, two-sided Mann-Whitney u-test), which holds true for 5 out of 10 individual periods $(0.025 \leq p \leq 0.083)$.

We thus conclude 
Result 3: We do not observe that the stakeholder duty increases transfers in our setting. On the contrary, there seems to be an effect in the opposite direction.

In a final step, we test the robustness of our previous results with parametric analyses and try to obtain some additional insight into the transfer decisions. Table 4 gives the estimation results from panel regressions explaining the actual transfers to charity in all treatments except Control. These estimations support our previous results: Competition decreases transfers significantly, while the introduction of the stakeholder duty does not increase transfers: The coefficient for the stakeholder duty is negative in all specifications and significant in most (Model 1, 2, and 4) 27

The panel regression also allows to investigate some developments over time. We observe a huge and highly significant increase in the last period. Models 2, 3, and 4 show that this last round effect is limited to the treatments with competition (see the significant interaction effect Last Period $\times$ Competition and the insignificant main effect Last Period). Furthermore, the estimations confirm that transfers decrease due to competition $($ Period $\times$ Competition $)$. With competition, managers face the risk of not being hired, which leads to additional adverse effects: Managers who had repeatedly not been chosen in previous rounds tended to give significantly higher amounts to charity ( $N$ Unemployed). We can only speculate whether this is caused by frustration, desire for revenge, image awareness or genuinely stronger concern for charity.

Models 3 and 4 also include a measure for personal sensitivity towards unjust behavior, as elicited using the Justice Sensitivity Questionnaire ${ }^{28}$ As might be expected, being sensitive to injustice is positively correlated with managers' transfers.

27 We do observe a positive interaction of stakeholder duty and competition (Stake $\times$ Competition), but it is insignificant and its net effect is negligible, given the negative coefficient for the main effect.

28 We were interested in the justice sensitivity scales from the perspectives of observers and perpetrators. Since both scales are significantly correlated in our sample (Spearman's rank correlation, $p<0.001$ with $\rho=0.5855$ ) we generated one overall scale using both perspectives (Cronbach's $\alpha=0.7609$ ) and used this for our Justice Sensitivity variable. Our results remain valid if we use only one of the sub-scales. 
Table 4.: Random effects GLS estimation of transfers to charity

\begin{tabular}{|c|c|c|c|c|}
\hline & (1) & $(2)$ & $(3)$ & $(4)$ \\
\hline Period & $\begin{array}{c}-9.1 \\
(20.382)\end{array}$ & $\begin{array}{c}38.6 \\
(30.330)\end{array}$ & $\begin{array}{c}38.6 \\
(30.347)\end{array}$ & $\begin{array}{c}38.6 \\
(30.365)\end{array}$ \\
\hline Last Period & $\begin{array}{c}1,406.0^{* * *} \\
(244.082)\end{array}$ & $\begin{array}{c}43.5 \\
(190.939)\end{array}$ & $\begin{array}{c}43.5 \\
(191.049)\end{array}$ & $\begin{array}{c}43.5 \\
(191.160)\end{array}$ \\
\hline Stake & $\begin{array}{c}-541.2^{*} \\
(281.100)\end{array}$ & $\begin{array}{c}-796.4 \\
(523.539)\end{array}$ & $\begin{array}{c}-938.9^{*} \\
(506.050)\end{array}$ & $\begin{array}{r}-1,002.4^{* *} \\
(479.185)\end{array}$ \\
\hline Competition & $\begin{array}{c}-1,807.2^{* * *} \\
(306.049)\end{array}$ & $\begin{array}{c}-1,753.9^{* * *} \\
(432.144)\end{array}$ & $\begin{array}{c}-2,032.9 * * * \\
(418.879)\end{array}$ & $\begin{array}{c}-2,205.2^{* * * *} \\
(408.586)\end{array}$ \\
\hline Period $\times$ Competition & & $\begin{array}{l}-99.4^{* *} \\
(38.866)\end{array}$ & $\begin{array}{c}-193.6^{* * *} \\
(41.570)\end{array}$ & $\begin{array}{c}-192.7^{* * * *} \\
(41.703)\end{array}$ \\
\hline Last Period $\times$ Competition & & $\begin{array}{c}2,833.0^{* * *} \\
(390.835)\end{array}$ & $\begin{array}{c}2,818.4^{* * *} \\
(385.416)\end{array}$ & $\begin{array}{c}2,818.3^{* * *} \\
(385.829)\end{array}$ \\
\hline Stake $\times$ Competition & & $\begin{array}{c}418.2 \\
(611.577)\end{array}$ & $\begin{array}{c}576.1 \\
(589.014)\end{array}$ & $\begin{array}{c}690.8 \\
(571.585)\end{array}$ \\
\hline $\mathrm{N}$ unemployed & & & $\begin{array}{l}494.0^{* * *} \\
(81.613)\end{array}$ & $\begin{array}{l}487.7^{* * *} \\
(81.652)\end{array}$ \\
\hline Justice Sensitivity & & & $\begin{array}{l}773.8^{* * *} \\
(155.394)\end{array}$ & $\begin{array}{l}734.0^{* * *} \\
(166.912)\end{array}$ \\
\hline Female & & & & $\begin{array}{c}239.6 \\
(317.229)\end{array}$ \\
\hline Age & & & & $\begin{array}{l}-93.4^{* *} \\
(44.757)\end{array}$ \\
\hline Constant & $\begin{array}{c}3,933.8^{* * *} \\
(284.496)\end{array}$ & $\begin{array}{c}3,935.1^{* * *} \\
(334.062)\end{array}$ & $\begin{array}{l}1,530.2^{* *} \\
(597.147)\end{array}$ & $\begin{array}{l}3,753.0^{* * *} \\
(1,078.475)\end{array}$ \\
\hline Observations & 1,740 & 1,740 & 1,740 & 1,740 \\
\hline Number of subjects & 241 & 241 & 241 & 241 \\
\hline Overall $R^{2}$ & 0.145 & 0.166 & 0.214 & 0.234 \\
\hline Prob $>\chi^{2}$ & $<0.001$ & $<0.001$ & $<0.001$ & $<0.001$ \\
\hline
\end{tabular}

Clusters on group level; robust standard errors in parentheses ${ }^{* * *} \mathrm{p}<0.01,{ }^{* *} \mathrm{p}<0.05,{ }^{*} \mathrm{p}<0.10$

$N$ unemployed is the number of periods a subject has been unemployed ( 0 in the first period). Data only from subjects in the role of active (chosen) manager. 19 managers were never chosen. An estimation with all data from the strategy method obtains qualitatively similar results (see Table 7 in the Appendix). 
Parametric analyses therefore confirm our previous results, and suggest

Result 4: Transfers increase significantly if managers have a higher justice sensitivity and if they had been unemployed for a longer period.

As a very last step we turn to the post-questionnaire, which contained various statements with five-level Likert items ("strongly disagree" to "strongly agree"). This questionnaire provides additional evidence that competition increased the desire of the managers to please the shareholders. In the treatments with competition, $56 \%$ and $67 \%$ of the managers agreed that "During the experiment it was important to me what the other side thought about me". In the treatments without competition only $23 \%$ and $31 \%$ of the managers agreed with this statement. Overall, managers cared significantly more about the way they were perceived by the shareholders if competition was present $(p>0.001$, two-sided Mann-Whitney u-test).

In addition we asked whether "Managers felt bound to the expectations of their shareholders". Managers should disagree with this statement, since all instructions informed subjects that "a manager is not bound by the expectations and demands of the shareholder". Indeed, in treatments without manager competition most subjects disagreed with this statement; only $9 \%$ or $13 \%$ of managers agreed. However, in treatments with manager competition, those numbers were $53 \%$ and $61 \%$, respectively. Thus, subjects in treatments with competition felt significantly more bound to the expectations of their shareholders (p $<0.001$, two-sided Mann-Whitney u-test).

Result 5: Managers were much more concerned about shareholders' perception if competition was present. Based on their perceived incentives they chose to abandon their stated duties and to conform to the shareholders' expectations. 


\section{Summary and Discussion}

We have conducted an experiment to shed light on some determinants of the efficacy of stakeholder legislation. In a dictator game variant with business framing, subjects were free to transfer any part of an exogenous endowment to the general public (represented by a charity) on behalf of their enterprise. In one condition, subjects were framed as owner-managers, in four others they were shareholders or managers required to take complementary steps towards this decision.

In treatments with one partner-matched manager, transfers to charity were significantly higher than in the Control with owner-managers. This may be read as a case of agency costs, which in turn were reduced to almost zero when managers had to compete for their position. Such competition induced behavior mostly indistinguishable from shareholder behavior in the absence of managers (subject to an end-game effect in the final repetition). On the one hand, shareholders hired managers that were less other-regarding, on the other hand managers conformed consciously to what they (rightly) thought shareholders would expect.

When additionally prompting managers to pay due consideration to stakeholders such as the general public - as in Sec. 4.1.1 of the German Corporate Governance Code - this did not happen. Managers behaved no different in the presence of this duty 29 This even held if the institutionalized incentive of competition was lacking; if managers responded to the legal provision at all, they did so by lowering their transfers to charity, leaving the latter in what was poignantly described as "the cold comfort of transparency without consequence" (Blount and Offei-Danso 2013: 654).

One potential explanation might be that increasing the salience of stakeholder inter-

29 Similarly, research on voluntary contribution games has shown that moral suasion requires sanctioning opportunities to sustain cooperation (Dal Bó and Dal Bó 2010). 
ests also increased the salience of shareholder interests. In our experiment managers were prompted to act in the "interest of the stakeholders [e.g. shareholders, employees, customers, general public]" where subjects might have read the order in which the different constituencies appeared as a ranking of priority. Thus the apparent "stakeholder frame" of Sec. 4.1.1 GCGC may also be a "shareholder frame", in that it also emphasizes shareholder interests. ${ }^{30}$ This points to the fact that in any given context, it may not be apparent which reference group a normative framing favors. In our experiment, as in reality, subjects may construe normative expectations quite differently than expected.

Our study tentatively suggests policy implications for the design of social enterprises such as benefit corporations. Lawmakers must be careful to consider incentives, and should think carefully about how to phrase the stakeholder duty. Because of the managers' incentive to please shareholders, it might be ill-advised for benefit corporations to empower only shareholders (see also André 2012). Given that benefit corporations sell a product, they can be financially successful, so their managers (especially if they are professionals) need not assume that all shareholders are other-regarding types - especially when investors are second-generation, without the personal sense of mission that the company's founders had. Once profit-interested investors make up part of the company's base, managers are best off maximizing shareholder value, just as in a classical corporation without any stakeholder duty. If potential investors anticipate that, they need not even fear the "benefit" label. As a consequence, benefit corporations cannot be relied upon as an automated screening device to effectively select pro-social shareholders. Instead, a company's vision has to be institutionalized in specific incentives to enforce the stakeholder duty ${ }^{31}$ Therefore, the

30 Also, one might contend that a stakeholder duty does not imply charitable giving, but rather farsighted investments into the company's reputation, its home base environment (e.g. improving worker supply in the future by investing in schools today) or quite generally any measures that benefit the company in the long run. Yet if stakeholder value was nothing but long-term shareholder value, its raison d'être were quite questionable. See our argument in Section II

31 Again, we should highlight the importance of also enabling management to serve societal purposes (even if pressured by profit-interested shareholders), but this is merely one side of the coin. See our 
incentive structure does deserve more careful attention by policy-makers, lest "the benefit corporation fails as a useful legal structure because it sets forth a general public benefit purpose, but provides the parties most affected by this purpose with no corresponding effective method for enforcing it." (Blount and Offei-Danso 2013: 669; Munch 2012: 189)

Regarding the stakeholder duty itself, our results shed some doubt on whether such an appeal will be helpful at all. Maybe stakeholders are better off if directors are not faced with a list of constituencies in which shareholders feature prominently at the very top (see Stout, 2012). Perhaps managers should be formally granted full discretion-which stakeholder duties usually confer upon them anyhow by some catch-all phrase like "other pertinent factors or the interests of any other group that [the directors] deem appropriate" (§ 301 (a) (2) MBCL). On the other hand, lawmakers may just want to remind management that shareholders, too, are stakeholders to be considered. Given the results of our study, however, such reminders are barely necessary as long as management acts under the threat of being sanctioned by shareholders, and shareholders only.

Only a number of countries have yet introduced social enterprise forms like the benefit corporation. Thus the empirical investigation of stakeholder duties is still in its infancy. Obviously our study can only be a first attempt at empirically analyzing stakeholder duties. While it allows to disentangle different aspects that are inevitably confounded in the field, it does invite complementary field studies to check the robustness and bolster the external validity of our findings. It also invites additional studies on the effects of stakeholder legislation in the presence of endogenous institutional choice. Since shareholders and managers self-select into benefit corporations, the net effect of stakeholder legislation may still be positive, even though our study had to abstract from these aspects to effectively isolate the restraining effect we were analyzing. For the time being, our results put a tentative question mark over the efficacy of "stakeholder" norms which put shareholders

Introduction. 
in first position and are enforced exclusively by them. 


\section{Bibliography}

Abbink, K. and H. Hennig-Schmidt (2006). Neutral versus loaded instructions in a bribery experiment. Experimental Economics 9(2), 103-121.

Adams, R. B., A. N. Licht, and L. Sagiv (2011). Shareholders and stakeholders: How do directors decide? Strategic Management Journal 32(12), 1331-1355.

André, R. (2012). Assessing the accountability of the benefit corporation: Will this new gray sector organization enhance corporate social responsibility? Journal of Business Ethics 110, 133-150.

Arlen, J., M. Spitzer, and E. Talley (2002). Endowment effects within corporate agency relationships. The Journal of Legal Studies 31(1), pp. 1-37.

Artz, N., J. Gramlich, and T. Porter (2012). Low-profit limited liability companies (L3Cs). Journal of Public Affairs 12(3), 230-238.

Bènabou, R. and J. Tirole (2010). Individual and corporate social responsibility. Economica $77(305), 1-19$.

Berle, A. and G. Means (1932). The Modern Corporation and Private Property. New York: Harcourt, Brace and World. also 2nd ed. 1967.

Berninghaus, S. K., W. Güth, and A. Kirstein (2008). Trading goods versus sharing money: An experiment testing whether fairness and efficiency are frame dependent. Journal of Neuroscience, Psychology, and Economics 1(1), 33-48.

Blount, J. and K. Offei-Danso (2013). The benefit corporation: A questionable solution to a non-existent problem. St. Mary's Law Journal 44, 617-670. 
Bolton, G. E. and A. Ockenfels (2000). ERC: A theory of equity, reciprocity, and competition. The American Economic Review 90(1), 166-193.

Burks, S. V. and E. L. Krupka (2012). A multimethod approach to identifying norms and normative expectations within a corporate hierarchy: Evidence from the financial services industry. Management Science 58(1), 203-217.

Dal Bó, E. and P. Dal Bó (2010). "Do the right thing:" the effects of moral suasion on cooperation. NBER Working Paper 15559.

DeCelestino, C. M. (2006). Krispy Kreme, Sarbanes-Oxley, and corporate greed. University of Miami Business Law Review 15, 225-245.

Dufwenberg, M., S. Gächter, and H. Hennig-Schmidt (2011). The framing of games and the psychology of play. Games and Economic Behavior 73(2), 459-478.

Eckel, C. C. and P. J. Grossman (1996). Altruism in anonymous dictator games. Games and Economic Behavior 16, 181-191.

Engel, C. (2011). Dictator games: a meta study. Experimental Economics 14, 583-610.

Fehr, E. and K. M. Schmidt (1999). A theory of fairness, competition and cooperation. The Quarterly Journal of Economics 114(3), 817-868.

Fischbacher, U. (2007). z-Tree: Zurich toolbox for ready-made economic experiments. Experimental Economics 10(2), 171-178.

Fiss, P. C. and E. J. Zajac (2004). The diffusion of ideas over contested terrain: The (non)adoption of a shareholder value orientation among German firms. Administrative Science Quarterly 49(4), 501-534.

Forsythe, R., J. L. Horowitz, N. E. Savin, and M. Sefton (1994). Fairness in simple bargaining experiments. Games and Economic Behavior 6(3), 347-369. 
Greenfield, K. and P. C. Kostant (2003). An experimental test of fairness under agency and profit-maximization constraints (with notes on implications for corporate governance). George Washington Law Review 71, 983-1024.

Greiner, B. (2004). An online recruitment system for economic experiments. In K. Kremer and V. Macho (Eds.), Forschung und wissenschaftliches Rechnen 2003, Volume 63 of GWDG Bericht. Göttingen: Gesellschaft für Wissenschaftliche Datenverarbeitung.

Hamman, J. R., G. Loewenstein, and R. A. Weber (2010). Self-interest through delegation: An additional rationale for the principal-agent relationship. American Economic Review $100(4), 1826-1846$.

Hansmann, H. and R. Kraakman (2000). The end of history for corporate law. Georgetown Law Journal 89, 439-468.

Jürgens, U., K. Naumann, and J. Rupp (2000). Shareholder value in an adverse environment: the German case. Economy and Society 29(1), 54-79.

Kanig, I. (2013). Sustainable capitalism through the benefit corporation: Enforcing the procedural duty of consideration to protect non-shareholder interests. Hastings Law Journal 64, 863-903.

Krupka, E. L. and R. A. Weber (2013). Identifying social norms using coordination games: Why does dictator game sharing vary? Journal of the European Economic Association 11(3), 495-524.

Manâa, M. (2010). Legal business history. In Law and Society Association Conference, Chicago, USA.

Mickels, A. (2009). Beyond corporate social responsibility: Reconciling the ideals of a 
for-benefit corporation with director fiduciary duties in the U.S. and Europe. Hastings International and Comparative Law Review 32, 271-303.

Munch, S. (2012). Improving the benefit corporation: How traditional governance mechanisms can enhance the innovative. Northwestern Journal of Law and Social Policy 7, 170-195.

Murray, J. H. (2012). Choose your own master: Social enterprise, certifications, and benefit corporation statutes. American University Business Law Review 2(1), 1-53.

Murray, J. H. (2013). Defending Patagonia: Mergers \& acquisitions with benefit corporations. Hastings Business Law Journal 9, 485-517.

Murray, J. H. and E. I. Hwang (2011). Purpose with profit: Governance, enforcement, capital-raising and capital-locking in low-profit limited liability companies. University of Miami Law Review 66, 1-52.

Plerhoples, A. (2012). Can an old dog learn new tricks? Applying traditional corporate law principles to new social enterprise legislation. Transactions: The Tennessee Journal of Business Law 13, 221-265.

Schmidt, W. and J. Meyer-Landrut (1961). § 70 AktG. In B. et al. (Ed.), Aktiengesetz: Großkommentar (2nd ed.)., pp. 430-445. Berlin: de Gruyter.

Schmitt, M., M. Gollwitzer, J. Maes, and D. Arbach (2005). Justice sensitivity: Assessment and location in the personality space. European Journal of Psychological Assessment $21(3), 202-211$.

Selten, R. (1967). Die Strategiemethode zur Erforschung des eingeschränkt rationalen Verhaltens im Rahmen eines Oligopolexperiments. In H. Sauermann (Ed.), Beiträge zur experimentellen Wirtschaftsforschung, pp. 136-168. Tübingen: Mohr. 
Shleifer, A. and R. W. Vishny (1997). A survey of corporate governance. The Journal of Finance 52, 737-783.

Stout, L. (2012). The Shareholder Value Myth: How Putting Shareholders First Harms Investors, Corporations, and the Public. San Francisco: Berrett-Koehler.

Timmerman, L., M. de Jongh, and A. Schild (2011). The rise of the social enterprise: How social enterprises are changing company law worldwide. In Muller, Zouridis, Frishman, and Kistemaker (Eds.), The Law of the Future and the Future of Law, pp. 305-319. Oslo: Torkel Opsahl.

Von Werder, A. (2010). Zusammenwirken von Vorstand und Aufsichtsrat. In Ringleb, Kremer, Lutter, and von Werder (Eds.), Kommentar zum Deutschen Corporate Governance Kodex (4th ed.)., pp. 351-554. München: Beck. 


\section{Appendix}

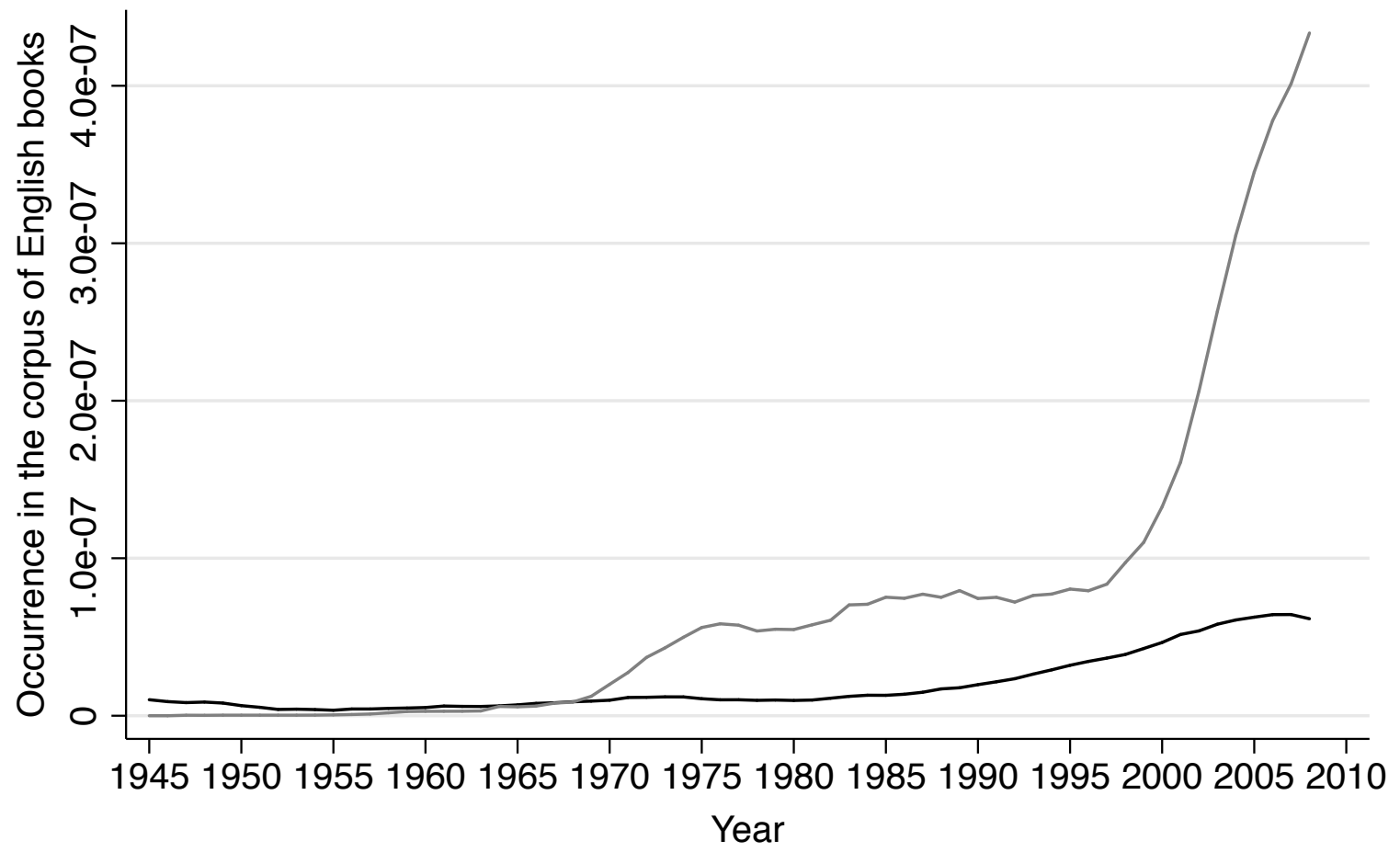

corporate greed

corporate social responsibility

Figure 2.: Occurrences of corporate greed and corporate social responsibility in the corpus of English books. Data taken from Google Books Ngram Viewer (https://books.google.com/ngrams/) 


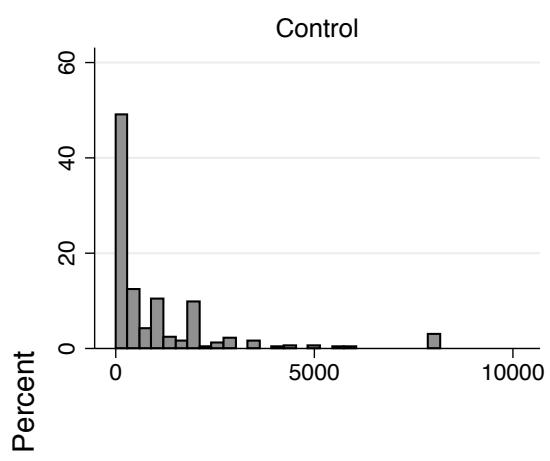

NoCompNoStake

NoCompStake
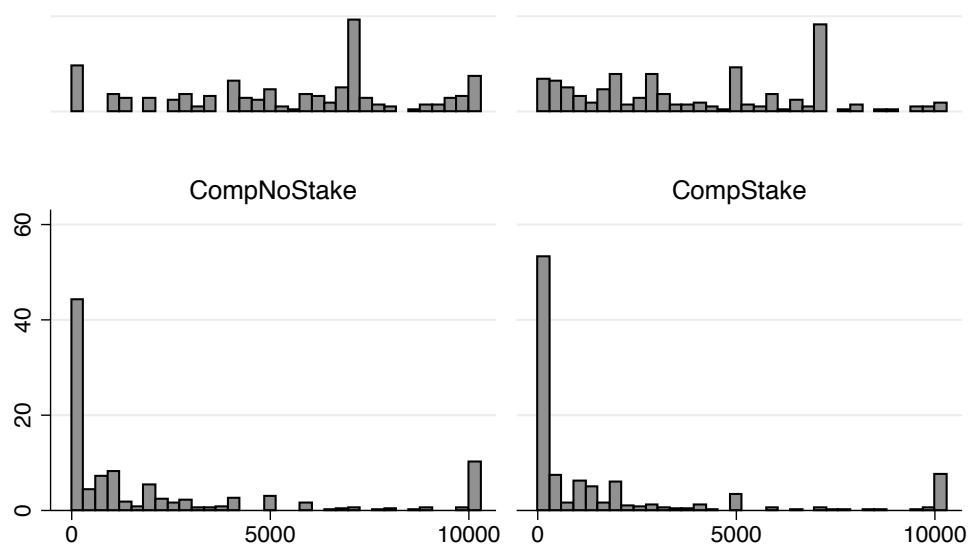

Figure 3.: Amount (out of 10,000) donated to Charity on Shareholder's behalf

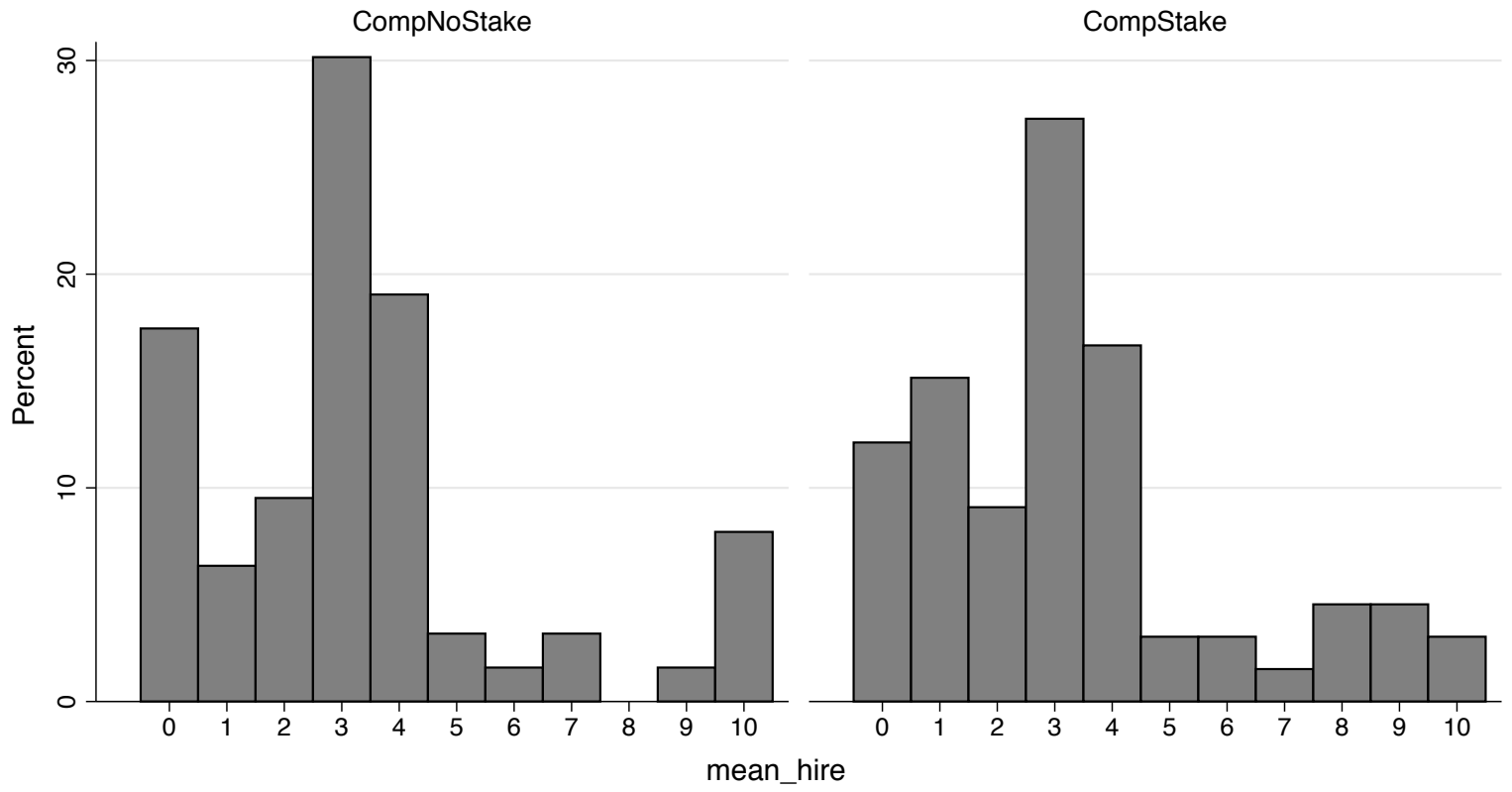

Figure 4.: Distribution of number of rounds in which managers were chosen in the Comptreatments 
Table 5.: Mixed effects logit estimation of the probability of being selected again

\begin{tabular}{|c|c|c|c|c|}
\hline & Coeff. & & Std. error & $\mathrm{p}$-value \\
\hline Constant & -.6362 & & .6944 & 0.360 \\
\hline Donation $_{t-1}$ & -.0010 & $* * *$ & .0003 & 0.004 \\
\hline Period & .1435 & & .0889 & 0.106 \\
\hline Donation $t-1 \times$ Period & .0001 & $* *$ & .00003 & 0.024 \\
\hline
\end{tabular}

$$
\mathrm{N}=344, \chi^{2}(3)=17.76, p=0.0005^{* * *}
$$

Note: Dependent variable is an indicator for whether the manager was chosen again at $t$. Data only from managers chosen at $(t-1)$ in either CompNoStake or CompStake. (Regression replicates table 3 without data from the last period.)

$$
\text { *** } \mathrm{p}<0.01,{ }^{* *} \mathrm{p}<0.05,{ }^{*} \mathrm{p}<0.10
$$

Table 6.: Mixed effects logit estimation of the probability of being selected again

\begin{tabular}{lcccc} 
& Coeff. & & Std. error & p-value \\
\hline \hline & & & & \\
Constant & -0.803 & $* * *$ & 0.2729 & 0.003 \\
PrevDonation & -0.0005 & $* * *$ & 0.0001 & 0.000 \\
Period & 0.0382 & & 0.0345 & 0.268 \\
PrevDonation $\times$ Period & 0.00003 & $* *$ & 0.00001 & 0.022 \\
\hline \hline
\end{tabular}

$$
\mathrm{N}=1161, \chi^{2}(2)=199.34, p=0.0000^{* * *}
$$

Note: Dependent variable is an indicator for whether the manager was chosen again at $t$. All data from either CompNoStake or CompStake. PrevDonation is the sum of previous donations from rounds in which the manager was chosen. (Regression replicates table 3 with complete data.)

$$
* * * \mathrm{p}<0.01,{ }^{* *} \mathrm{p}<0.05,{ }^{*} \mathrm{p}<0.10
$$


Table 7.: Random effects GLS estimation of transfers to charity

\begin{tabular}{|c|c|c|c|c|}
\hline & (1) & $(2)$ & $(3)$ & (4) \\
\hline Period & $\begin{array}{c}19.8 \\
(21.808)\end{array}$ & $\begin{array}{c}38.6 \\
(30.309)\end{array}$ & $\begin{array}{c}38.6 \\
(30.321)\end{array}$ & $\begin{array}{c}38.6 \\
(30.333)\end{array}$ \\
\hline Last Period & $\begin{array}{c}2,316.7^{* * *} \\
(277.177)\end{array}$ & $\begin{array}{c}43.5 \\
(190.811)\end{array}$ & $\begin{array}{c}43.5 \\
(190.885)\end{array}$ & $\begin{array}{c}43.5 \\
(190.959)\end{array}$ \\
\hline Stake & $\begin{array}{l}-499.0^{* *} \\
(245.439)\end{array}$ & $\begin{array}{c}-796.4 \\
(523.189)\end{array}$ & $\begin{array}{c}-924.7^{*} \\
(506.060)\end{array}$ & $\begin{array}{l}-976.2^{* *} \\
(482.709)\end{array}$ \\
\hline Competition & $\begin{array}{c}-1,804.6^{* * *} \\
(292.199)\end{array}$ & $\begin{array}{c}-2,218.1^{* * *} \\
(398.440)\end{array}$ & $\begin{array}{c}-1,909.4^{* * * *} \\
(379.452)\end{array}$ & $\begin{array}{c}-2,061.6^{* * * *} \\
(368.027)\end{array}$ \\
\hline Period $\times$ Competition & & $\begin{array}{c}-28.5 \\
(41.974)\end{array}$ & $\begin{array}{c}-242.3^{* * *} \\
(42.577)\end{array}$ & $\begin{array}{c}-240.9 * * * \\
(42.615)\end{array}$ \\
\hline Last Period $\times$ Competition & & $\begin{array}{c}3,436.3^{* * *} \\
(373.548)\end{array}$ & $\begin{array}{c}3,385.4^{* * *} \\
(373.182)\end{array}$ & $\begin{array}{c}3,385.8^{* * * *} \\
(373.335)\end{array}$ \\
\hline Stake $\times$ Competition & & $\begin{array}{c}449.7 \\
(582.044)\end{array}$ & $\begin{array}{c}525.3 \\
(567.286)\end{array}$ & $\begin{array}{c}608.5 \\
(550.854)\end{array}$ \\
\hline N unemployed & & & $\begin{array}{l}458.1^{* * *} \\
(62.504)\end{array}$ & $\begin{array}{l}455.1^{* * *} \\
(62.447)\end{array}$ \\
\hline Justice Sensitivity & & & $\begin{array}{l}697.0^{* * *} \\
(141.596)\end{array}$ & $\begin{array}{l}667.5^{* * *} \\
(149.971)\end{array}$ \\
\hline Female & & & $(276.602)$ & 181.6 \\
\hline Age & & & & $\begin{array}{c}-78.4^{*} \\
(43.398)\end{array}$ \\
\hline Constant & $\begin{array}{c}3,662.7^{* * *} \\
(287.086)\end{array}$ & $\begin{array}{c}3,935.1^{* * *} \\
(333.839)\end{array}$ & $\begin{array}{c}1,768.8^{* * *} \\
(560.019)\end{array}$ & $\begin{array}{l}3,633.9^{* * *} \\
(1,037.428)\end{array}$ \\
\hline Observations & 1,740 & 1,740 & 1,740 & 1,740 \\
\hline Number of subjects & 260 & 260 & 260 & 260 \\
\hline Overall $R^{2}$ & 0.148 & 0.174 & 0.223 & 0.231 \\
\hline Prob $>\chi^{2}$ & $<0.001$ & $<0.001$ & $<0.001$ & $<0.001$ \\
\hline
\end{tabular}

Clusters on group level; robust standard errors in parentheses ${ }^{* * *} \mathrm{p}<0.01,{ }^{* *} \mathrm{p}<0.05,{ }^{*} \mathrm{p}<0.10$

$N$ unemployed is the number of periods a subject has been unemployed ( 0 in the first period). All responses elicited by strategy method are used. 


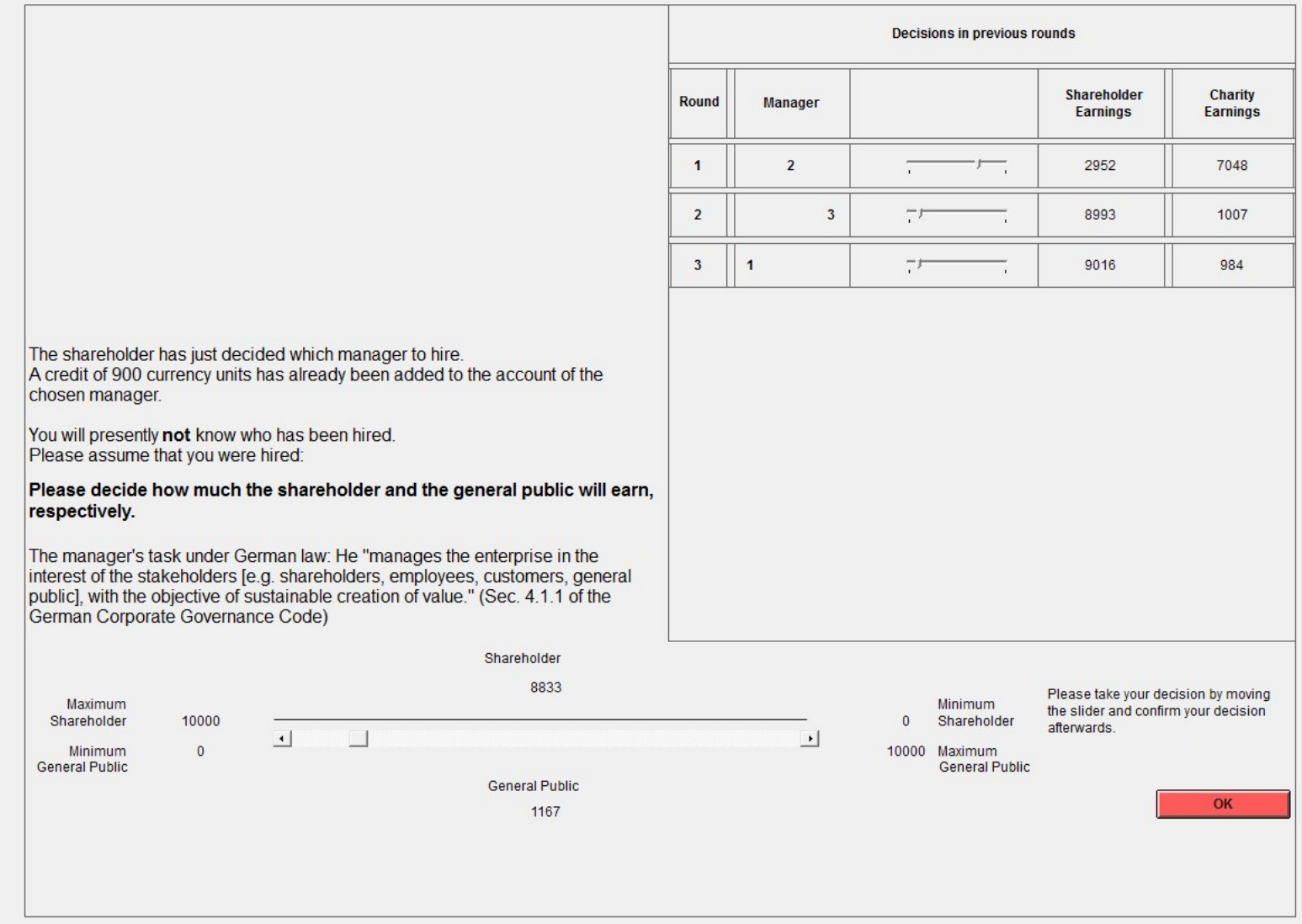

Figure 5.: Screenshot: Allocation decision by the manager 


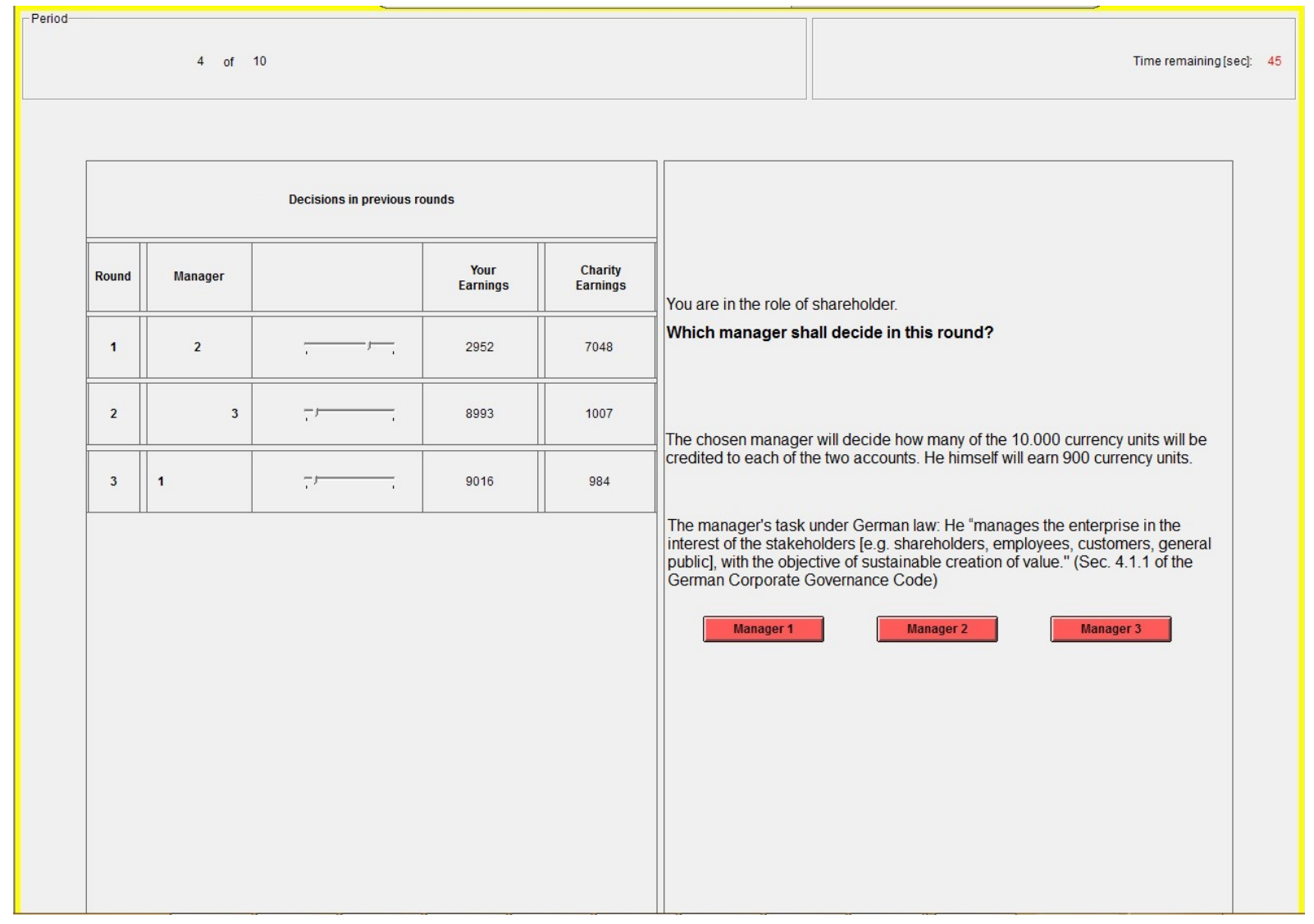

Figure 6.: Screenshot: Selection of a manager 


\section{Instructions Part 1}

Welcome to today's experiment. Depending on your decisions and those of other participants you will earn money in this experiment. Therefore, it is very important that you read these instructions carefully. Once all participants have read the instructions you will be asked to answer some control questions to check whether all the participants have understood the instructions.

During the whole experiment it is prohibited to communicate with other participants. Please raise your hand and address one of the persons in charge if you have any questions. Any violation of this rule will result in exclusion from this experiment and all possible payments.

During this experiment all monetary amounts will be given in "Taler". At the end of the experiment the total amount of Talers earned will be converted to Euros at the following rate

\section{Taler $=1$ EURO}

The experiment consists of over several rounds. [During this experiment you will interact with other participants, who will be assigned to you at random. You will, however, receive no information about their identity; conversely, no participant will receive information about your identity.] OR [In every round you will decide on your own, independent of all other participants.]

In every round you will make a business decision in a role that is yet to be assigned to you. As in reality, this decision affects both, the company owner's revenues and the general public. Therefore, the computer sets up two accounts for each participant: one for the participant himself and one for the general public (the so-called donation account). Any credit balance on the donation account will benefit a charitable organisation, which has the seal ("audited and recommended") of the German central institute for social questions (Deutsches Zentralinstituts für soziale Fragen, DZI).

At the beginning, both accounts will have a credit balance of 0 Taler. If there is any positive balance on the donation account at the end of this experiment, we will put the equivalent Euro amount inside a glass container. The credit balance on your own account will then be converted to Euros and paid out to you in cash. No participant will be allowed to place additional money in the container before, during or after the payment takes place.

After the payments, we will make an online bank transfer of the collected donations in the glass container to the previously mentioned non-profit organization. You are welcome to attend this process. In any case, we kindly ask the participant in cabin 24 to supervise this transaction. 


\section{Instructions Part 2 (Control)}

You will make decisions in the following role:

You are the owner of a company in Germany, which you manage on your own.

You will keep this role for the 10 rounds of the experiment.

\section{Basic Principle}

In each round, you split an amount of 10,000 Taler between yourself and the general public. Hence, you must reduce the amount that could benefit the donation account. Conversely, the more Taler you allocate to the donation account, the less that flows into your account.

\section{Implementation Details}

Each round happens as follows:

You see the decisions made by yourself in the previous rounds (this is not the case for the first round) and then make a binding decision on how much you would like to assign to your account as well as to the donation account.

At the end of a round you will receive an overview on your decision.

The experiment ends after 10 rounds have been played. One round will then be chosen at random and the payments calculated as follows: You receive the amount that you assigned to your own account in the drawn round.

After each participant has been paid out, we will count the total amount of donations in the glass container and transfer the money to the non-profit organization.

\section{Instructions Part 2 (NoComp**)}

At the beginning of the experiment, the computer will assign one out of two possible roles to each participant at random. The role is then fixed for the rest of the experiment. There will be two participants interacting with each other at a time. One of them will play the role of a

Shareholder meaning he/she owns a company in Germany. Shareholders must hire a manager who manages the company under German law for them.

The other will take decisions in the role of a

Manager who is responsible for independently managing the enterprise. According to German law, a manager is not bound to the expectations and demands of the shareholder. 
AdD the FOllowing in Stake [; rather he "manages the enterprise in the interest of the stakeholders (e.g. shareholders, employees, customers, general public), with the objective of sustainable creation of value." (Sec. 4.1.1 of the German Corporate Governance Code)]

In short: the computer will randomly generate groups with two participants each. It will also assign roles to each group member at random. One group member will act in the role of a shareholder, while the other will act in the role of a manager. This group and role assignment will remain the same throughout all rounds and participants keep their name until the end. Thereafter, the 10 rounds of the game will start.

\section{Basic Principle}

In each round, the shareholder hires a manager who splits 10,000 Taler between the shareholder and the general public. Hence, the manager must reduce the amount that could benefit the donation account. Conversely, this means that the more Taler allocated to the donation account, the less that flows into the shareholder's account.

\section{Implementation Details}

Each round happens as follows:

1. The shareholder observes the decisions made by the manager, hired in the previous rounds (this is not the case for the first round) and hires the manager.

2. The manager sees his decisions made in the previous rounds (this is not the case for the first round) before making a binding decision about the amount to add to the shareholder's account as well as to the donation account.

At the end of each round, everyone will get an overview on the manger's decision. The experiment ends after 10 rounds. Then, one round will be randomly chosen and the payments calculated as follows:

- The shareholder receives the amount allocated to his/her account by the chosen manager during this round.

- Regardless of the draw the manager receives 300 Taler for each round - the manager's decisions have no effect on the amount paid.

After each participant has been paid out, we will count the total amount of donations in the glass container and transfer the money to the non-profit organization. 


\section{Instructions Part 2 (Comp**)}

At the beginning of the experiment, the computer will assign one out of two possible roles to each participant at random. The role is then fixed for the rest of the experiment. There will be four participants interacting with each other. One of them will play the role of a

Shareholder meaning he/she owns a company in Germany. Shareholders must hire a manager who manages the company under German law for them.

The other three will take decisions in the role of a

Manager who is responsible for independently managing the enterprise. According to German law, a manager is not bound to the expectations and demands of the shareholder. AdD THE FOLLOWING IN STAKe [; rather he "manages the enterprise in the interest of the stakeholders (e.g. shareholders, employees, customers, general public), with the objective of sustainable creation of value." (Sec. 4.1 .1 of the German Corporate Governance Code)]

In short: the computer will randomly generate groups with four participants each. It will also assign at random the role of the shareholder to one subject and at random to the others to the roles of the three managers manager 1, manager 2 and manager 3. This group and role assignment will remain the same throughout all rounds. Managers will also keep their name until the end. Thereafter, the 10 rounds of the game will start.

\section{Basic Principle}

In each round, the shareholder hires a manager who splits 10,000 Taler between the shareholder and the general public. Hence, the manager must reduce the amount that could benefit the donation account. Conversely, this means that the more Taler allocated to the donation account, the less that flows into the shareholder's account.

\section{Implementation Details}

Each round happens as follows:

1. The shareholder observes the decisions made by the managers hired in the previous rounds (this is not the case for the first round) and hires one of the three managers who has to decide in this round.

2. At first, the three managers will not receive information on the shareholder's decision and everyone decides as if he/she was hired: Everyone sees the decisions made by the managers hired in the previous rounds (this is not the case for the first round) before making a binding decision about the amount to add to the shareholder's account as well as to the donation account. 
Of the three decisions by the managers only the one of the manager hired by the shareholder is relevant. At the end of each round, every group member will get an overview of the hired manager and the manager's decision.

At the end of each round, everyone will get an overview on which manager was hired and the manager's decision. The experiment ends after 10 rounds. Then, one round will be randomly chosen and the payments calculated as follows:

- The shareholder receives the amount allocated to his/her account by the chosen manager during this round.

- Regardless of the draw each manager receives 900 Taler for each round in which he/she was chosen by the shareholder - the manager's decisions have no effect on the amount paid.

After each participant has been paid out, we will count the total amount of donations in the glass container and transfer the money to the non-profit organization. 